\title{
Features of heritable disorders of connective tissue in children with acute rheumatic fever and rheumatic heart disease
}

\section{Oksana Boyarchuk}

Department of Children's Diseases and Paediatric Surgery, I. Horbachevsky Ternopil National Medical University, Ternopil, Ukraine

\begin{abstract}
Objectives: Heritable disorders of connective tissue (HDCT) are associated with morphological and functional disorders of different organs and systems. The aim of our study was to determine the clinical signs of heritable disorders of connective tissue and oxyproline levels in children with acute rheumatic fever (ARF) and rheumatic heart disease (RHD).

Material and methods: A total of 155 patients aged 4 to 17 years participated in the study: 23 with ARF, 78 with RHD, and 54 healthy patients with a history of ARF. All patients underwent a standardized examination protocol, which consisted of a detailed medical history recorded by the physician, general and special laboratory tests, electrocardiogram, echocardiography, and Doppler echocardiography. Special attention was paid to the clinical signs of HDCT. The intensity of the metabolic processes in the connective tissue was evaluated by serum oxyproline levels.

Results: The signs of HDCT were revealed in 121 (78.1\%) of the patients with ARF and RHD. Among cardiovascular manifestations, we observed mitral valve prolapse most often - in 91 (58.7\%) patients. Musculoskeletal anomalies were observed in 94 (60.7\%) patients. Both groups of patients with ARF and RHD had elevated mean serum oxyproline levels.

Conclusions: Children with acute rheumatic fever and rheumatic heart disease presented with a number of signs characteristic of heritable connective tissue disorders. The cardiovascular and musculoskeletal system changes are the most frequent among all features of HDCT. Elevated levels of serum oxyproline in patients with ARF and RHD confirm connective tissue disorders. Children with manifestations of HDCT are at the risk of ARF and RHD development.
\end{abstract}

Key words: acute rheumatic fever, rheumatic heart disease, heritable disorders of connective tissue.

\section{Introduction}

More than 200 heritable disorders of connective tissue (HDCT) have been described so far [1]. These disorders are caused by mutations of the genes responsible for building connective tissues and affecting collagen, elastin, muco-polysaccharides, or enzymes regulating their metabolism [2, 3]. Disorders in connective tissue development leads to changes in homeostasis at all levels of metabolism and, subsequently, to morphological and functional disorders of different organs and systems.

Connective tissue is the protein-rich tissue, a scaffolding of all internal organs; it supports organs and other parts of the body, and forms the skeleton and skin.
In HDCT, those organs and systems that are rich in connective tissue are the most affected: skin, bones, joints, heart, blood vessels, lungs, eyes, and ears.

There are different types of HDCT. The most recognized are: Ehlers-Danlos syndrome, Marfan syndrome, osteogenesis imperfecta, Stickler syndrome, and fibromuscular dysplasia [3]. Underlying genetic mutations have been identified for many disorders of the connective tissue $[4,5]$.

Heritable disorders of connective tissue is often associated with heart abnormalities such as: mitral valve prolapse, mildly dilated aortic root, bilateral stenosis of the carotids, and aortic dilation [5]. These patients are 
have high probability of developing bacterial endocarditis and rheumatic heart disease (RHD) [6].

Autoimmune disorders also impact connective tissue. The pathogenetic mechanisms of acute rheumatic fever (ARF) include systemic disorganization of connective tissue [7]. First, there is depolymerization of the ground substance of connective tissue with the accumulation of acidic mucopolysaccharides, which, when progressing, leads to the disorganization of collagen fibers, their swelling, and collapse of collagen and the fibrinoid scaffolding [7]. This process is most pronounced and progressive in the heart and blood vessels. Incidentally, carditis and polyarthritis are the most frequently observed symptoms among those listed in the Jones criteria of ARF $[8,9]$.

In children with congenital connective tissue disorder, collagen fibers will be more accessible to destruction and more vulnerable to the inflammatory process. Increased levels of antibodies to $M$-protein, collagen type I, and myosin were found in patients with ARF [10]. Levels of these antibodies in patients with ARF were significantly higher than in patients with streptococcal nasopharyngeal infections [11]. Patients with ARF and significantly elevated levels of antibodies to collagen type I and fibronectin have subsequently developed heart defects.

Thus, the disorganization of connective tissue plays a significant role in the pathogenesis of ARF, and heritable disorders of connective tissue can be a risk factor for both ARF and chronic rheumatic heart disease (RHD), along with other predictors of these diseases [12].

Oxyproline (OXYP), as a major collagen amino acid, is an important component of the connective tissue and one of the products of its metabolism. Its concentration in the blood may be a marker of connective tissue disorders [13].

\section{Objectives}

The aim of our study was to determine the clinical signs of heritable disorders of connective tissue and oxyproline level in children with acute rheumatic fever and rheumatic heart disease.

\section{Material and methods}

A total of 155 patients participated in the study: I group $n=23$ - with ARF mean age $11.78 \pm 4.08$ years, II group $n=78$ - with RHD mean age $15.8 \pm 1.5$ years, III group $n=54$ healthy patients mean age $14.15 \pm 2.80$ years - with a history of ARF, and IV control group $n=30$ healthy patients without history of ARF.

Acute rheumatic fever was diagnosed according to the Jones criteria [14-16], and RHD according to World
Heart Federation criteria [17]. Rheumatic heart disease was diagnosed in patients using comprehensive clinical and echocardiographic Doppler examination. Subclinical rheumatic carditis was diagnosed in children with rheumatic cardiac lesions but no history of ARF, after exclusion of other potential causes (congenital heart disease, cardiomyopathy, infective endocarditis, etc.). In patients with a history of ARF $(n=54)$, comprehensive clinical and echocardiography examination did not reveal any cardiac lesions.

All patients underwent standardized examination protocol, which consisted of a detailed medical history recorded by the physician, general and special laboratory tests, electrocardiogram, echocardiography, and Doppler echocardiography. Special attention was paid to clinical signs of HDCT $[3,5]$. Emphasis was placed on the cardiovascular and musculoskeletal signs of HDCT. The physical examination included a standardized Beighton score for joint hypermobility and a thorough examination of the skin [18]. A Beighton score of 4 or more was considered as sign of joint hypermobility.

The intensity of metabolic processes in the connective tissue was evaluated using levels of collagen breakdown products, in particular, serum oxyproline, in 16 patients with ARF, 54 patients with RHD, and in 45 healthy patients with previous history of ARF [19]. For comparison, oxyproline levels were determined in 30 healthy controls.

Ethical approval for the study was given by the Research Ethics Committee of I. Horbachevsky Ternopil National Medical University. Parents of the children participating in this study gave their informed consent.

The study conformed to the principles outlined in the WMA Declaration of Helsinki.

\section{Statistical analyses}

The results were analyzed using Statistica StatSoft 6.0 software package. Normal distribution of the sample, the mean value (M), and the standard deviation (SD) were calculated. Student's t-test $(t)$ was used to compare the averages. The significance level of the tests was set at $\alpha=0.05$.

\section{Results}

The signs of HDCT were revealed in 121 (78.1\%) patients. However, there were not enough criteria to establish a specific diagnosis of HDCT (e.g. Ehlers-Danlos syndrome, Marfan syndrome) [3]. Cardiovascular and musculoskeletal signs of HDCT in patients with ARF and RHD are presented in Table I.

Mitral valve prolapse (MVP) was the most frequently observed sign of RHD in the HDCT group of pa- 
Table I. Signs of heritable disorders of connective tissue in patients with acute rheumatic fever (ARF) and rheumatic heart disease (RHD)

\begin{tabular}{|c|c|c|c|c|c|c|}
\hline \multirow[t]{2}{*}{ Signs } & \multicolumn{2}{|c|}{$\begin{array}{c}\text { ARF } \\
(n=23)\end{array}$} & \multicolumn{2}{|c|}{$\begin{array}{c}\text { RHD } \\
(n=78)\end{array}$} & \multicolumn{2}{|c|}{$\begin{array}{l}\text { Healthy subjects with } \\
\text { history of ARF } \\
(n=54)\end{array}$} \\
\hline & $n$ & $\%$ & $n$ & $\%$ & $n$ & $\%$ \\
\hline \multicolumn{7}{|l|}{ Cardiovascular signs } \\
\hline Mitral valve prolapse & 12 & 52.2 & 44 & 56.4 & 35 & 64.8 \\
\hline Left ventricular false tendon & 10 & 43.5 & 35 & 44.9 & 24 & 44.4 \\
\hline Bicuspid aortic valve & - & - & 2 & 2.6 & - & - \\
\hline Dysplastic aortic valve & 1 & 4.3 & - & - & 1 & 1.9 \\
\hline Idiopathic dilatation of the pulmonary artery & - & - & 1 & 1.3 & - & - \\
\hline \multicolumn{7}{|l|}{ Musculoskeletal anomalies } \\
\hline Joint hypermobility & 9 & 39.1 & 37 & 47.4 & 18 & 33.3 \\
\hline Thoracic scoliosis & 2 & 8.7 & 16 & 20.5 & 5 & 9.3 \\
\hline Posture defects & 7 & 30.4 & 37 & 47.4 & 24 & 44.4 \\
\hline Flat feet & 2 & 8.7 & 5 & 5.8 & 3 & 5.6 \\
\hline Chest deformity & 2 & 8.7 & 4 & 5.1 & 3 & 5.5 \\
\hline Nasal septum deviation & 1 & 4.3 & 4 & 5.1 & 3 & 5.5 \\
\hline Muscle hypotonia & 6 & 26.1 & 12 & 15.4 & 8 & 14.8 \\
\hline \multicolumn{7}{|l|}{ Other signs } \\
\hline Hypokinetic type of gallbladder dysfunction & 10 & 43.5 & 37 & 47.4 & 34 & 63.0 \\
\hline Nephroptosis & 2 & 8.7 & 15 & 19.2 & 7 & 13.0 \\
\hline Distention of the renal calyces and/or pelvis & 1 & 4.3 & 11 & 14.1 & 3 & 5.5 \\
\hline Umbilical hernias & 1 & 4.3 & - & - & 1 & 1.9 \\
\hline Myopia & 1 & 4.3 & 4 & 5.1 & 2 & 3.7 \\
\hline Recurrent nasal bleeding of vascular origin & 1 & 4.3 & 2 & 2.6 & - & - \\
\hline Retinal angiopathy & 2 & 8.7 & 7 & 9.0 & 3 & 5.6 \\
\hline
\end{tabular}

tients and was confirmed in $58.7 \%(n=91)$ of patients. In $72.5 \%(n=66)$ of patients MVP was mild, and in $27.5 \%$ $(n=25)$ it was moderate. A moderate degree of mitral regurgitation occurred more often in patients with RHD, and it may be also a result of the rheumatic process. Left ventricular false tendon was revealed in 69 (44.5\%) patients. In some cases, MVP was associated with leaflet chordal elongation, mitral valve leaflets elongation, and increased leaflet mobility. In singular cases we detected a rudimentary Eustachian valve of the inferior vena cava, Chiari network, a prominent crista, an idiopathic dilatation of the pulmonary artery, and a dysplastic aortic valve.

Musculoskeletal abnormalities were found in 94 (60.7\%) patients. Joint hypermobility was revealed in $64(41.3 \%)$ patients, common posture defects were detected in 68 (43.9\%) patients, and thoracic scoliosis with different degrees of severity in 18 (14.8\%) patients. Less frequently, chest deformity, flat feet, and nasal septum deviation were observed.

Ultrasound examination of the internal organs revealed signs of hypokinetic type of gallbladder dysfunction in $52.3 \%(n=81)$ patients. Nephroptosis was detected in $15.5 \%(n=24)$ and distention of the renal calyces and/or pelvis in $9.7 \%(n=15)$ of patients.

Among other signs, in some cases we found umbilical hernias, myopia, recurrent nasal bleeding of vascular origin, and retinal angiopathy (Table I).

The mean levels of serum oxyproline are shown in Table II.

The highest levels of oxyproline were detected in the patients with ARF, in whom it was twice as high as in the controls $(p<0.001)$. In children with RHD, the mean oxyproline levels were also significantly higher than in the controls $(p<0.01)$. In healthy children with a history of $A R F_{2}$ the level of OXYP remained significantly higher 
Table II. Oxyproline levels in serum of children with acute rheumatic fever (ARF) and rheumatic heart disease (RHD) $(M \pm S D)$

\begin{tabular}{|lccc|}
\hline Group of patients & $n$ & Oxyproline, $\mu \mathrm{mol} / \mathrm{l}$ & $p$ \\
\hline Controls & 30 & $29.63 \pm 8.69$ & \\
\hline ARF & 16 & $61.04 \pm 26.60$ & $<0.001$ \\
\hline RHD & 54 & $52.86 \pm 24.67$ & $<0.01$ \\
\hline $\begin{array}{l}\text { Healthy with } \\
\text { a history of ARF }\end{array}$ & 45 & $41.27 \pm 24.06$ & $<0.05$ \\
\hline
\end{tabular}

than in controls $(p<0.05)$, while it was significantly lower than in patients with ARF $(p<0.05)$.

\section{Discussion}

In this study, children with ARF and RHD demonstrated a high percentage (78.1\%) of HDCT features, which chiefly manifested in the form of changes of cardiovascular and musculoskeletal systems. None of these patients met the diagnostic criteria for any of the known HDCT types, although they have one or more features of HDCT. Glesby and Pyeritz [20] described an „overlap” among HDCT and proposed the acronym „MASS phenotype" to emphasize involvement of the mitral valve, aorta, skeleton, and skin.

Autoimmune disorders also affect connective tissue. There is a correlation between the severity of destructive processes in the connective tissue and antibody formation, which explains the higher frequency of development of autoimmune reactions, including rheumatic diseases, in children with HDCT [21]. Patients with degenerative mitral valve disease are more likely to develop bacterial endocarditis, and $\operatorname{RHD}[6,22]$. A dysplastic valve or other structural heart abnormalities can lead to changes in blood flow or development of blood flow turbidity, which makes the valves even more susceptible to inflammatory and degenerative lesions.

At the same time, the diagnosis of ARF in children with HDCT is difficult, often leading to over-diagnosis. Mitral valve prolapse and left ventricular false tendon have characteristic auscultatory phenomena, sometimes leading to impaired cardiac rhythm and conduction, which can be misinterpreted in a child with fever on the background of viral or bacterial infections.

Timely diagnosis of MVP and detection of MASS phenotype are very important to prevent incidences of misdiagnosis. For the diagnosis of ARF in patients with MVP, following a checklist of diagnostic criteria for ARF and the mandatory Doppler echocardiographic examination to identify signs of rheumatic lesions (valvulitis) are essential.
We include left ventricular false tendon on the list of the HDCT features because we have often seen other signs of CTD in children with HDCT, although Ferrer et al. [23] suggested that this is a normal finding in children, with no pathologic consequences except for an innocent murmur.

The other features of HDCT include skin hyperextensibility, vascular and soft tissue fragility, easy bruising, atrophic scars, hip or shoulder dislocation, and severe osteopenia [2, 3]. Severe osteopenia was reported in adult patients with Ehlers-Danlos syndrome [4]. Observations also pointed to an association between osteopenia and chronic heart failure [24].

The elevated serum levels of OXYP, a marker of bone metabolism, corroborates dysplastic changes [1]. Its highest values were found in children with ARF, where it was twice as high as controls. High levels of OXYP were also observed in children with RHD and in the group of patients with a history of ARF. Increased concentration of free OXYP in the blood of patients with CTD was reported and linked to a shift towards catabolic processes [21]. Literature also points out the role of connective tissue dysplasia in the development of ARF and RHD, suggesting that impaired collagen and elastin production, and increased enzyme activity may affect the severity and duration of the disease [21].

The bicuspid aortic valve (BAV), the most common congenital heart disease, may predispose to rheumatic lesions. Wang and Wang [25] reported that BAV are more frequently found in the Chinese population. In children the diagnosis of BAV points to the need for follow-up due to the possibility of developing not only bacterial endocarditis, but also ARF and RHD [25]. Previous or recurrent streptococcal infections and BAV in children and adults should encourage echocardiographic control, especially in children and young adults with signs of HDCT, because this group require a complex of measures regarding the development ARF and RHD prevention.

\section{Conclusions}

Clinical signs of heritable disorders of connective tissue were found in $78.1 \%$ of children with acute rheumatic fever and rheumatic heart disease. Cardiovascular and musculoskeletal system changes are the most frequent among all features of HDCT. The elevated levels of serum oxyproline in patients with ARF and RHD may confirm connective tissue disorder. Children with manifestations of HDCT are at risk of ARF and RHD development.

The author declares no conflict of interest. 


\section{References}

1. Kuivaniemi H, Tromp G, Prockop D. Mutation in collagen genes: causes of rare and some common diseases in humans. FASEB J 1991; 5: 2052-2060, DOI:10.1096/fasebj.5.7.2010058.

2. Inamadar AC, Palit A. Cutaneous signs in heritable disorders of the connective tissue. Indian I Dermatol Venereol Leprol 2004; 70: 253-255.

3. Bascom R, Schubart JR, Mills S, et al. Heritable disorders of connective tissue: Description of a data repository and initial cohort characterization. Am J Med Genet A 2019; 179: 552560, DOI:10.1002/ajmg.a.61054.

4. Malfait F, Francomano C, Byers P, et al. The 2017 international classification of the Ehlers-Danlos syndromes. Am J Med Genet C Semin Med Genet 2017; 175: 8-26, DOI: 10.1002/ ajmg.c.31552.

5. Blackburn PR, Xu Z, Tumelty KE, et al. Bi-allelic Alterations in AEBP1 Lead to Defective Collagen Assembly and Connective Tissue Structure Resulting in a Variant of Ehlers-Danlos Syndrome. Am J Hum Genet 2018; 102: 696-705, DOI: 10.1016/j. ajhg.2018.02.018.

6. Komorovsky R, Boyarchuk O, Synytska V. Streptococcus gordonii-associated infective endocarditis in a girl with Barlow's mitral valve disease. Cardiol Young 2019; 29: 1099-1100, DOI: 10.1017/S1047951119001434.

7. Cunningham MW. Rheumatic fever, autoimmunity, and molecular mimicry: the streptococcal connection. Int Rev Immunol 2014; 33: 314-329, DOI: 10.3109/08830185.2014.917411.

8. Boyarchuk O, Boytsanyuk S, Hariyan T. Acute rheumatic fever: clinical profile in children in western Ukraine. J Med Life 2017; 10: $122-126$

9. Boyarchuk O, Hariyan T, Kovalchuk T. Clinical features of rheumatic heart disease in children and adults in Western Ukraine. Bangladesh Journal of Medical Science 2019; 18: 87-93, DOI: 10.3329/bjms.v18i1.39556.

10. Guilherme L, Kalil J. Rheumatic fever: from innate to acquired immune response. Ann N Y Acad Sci 2007; 1107: 426-433, DOI: 10.1196/annals.1381.045.

11. Martins TB, Hoffman JL, Augustine NH, et al. Comprehensive analysis of antibody responses to streptococcal and tissue antigens in patients with acute rheumatic fever. Int Immunol 2008; 20: 445-452, DOI: 10.1093/intimm/dxn004.

12. Boyarchuk O, Komorovsky R, Kovalchuk T, Denefil O. Socio-demographic and medical predictors of rheumatic heart disease in a low risk population. Pediatr Pol 2018; 93: 325-330, DOI: 10.5114/polp.2018.77998.

13. Bebeshko VG, Bruslova KM, Volodina TT, et al. Features of clinical symptoms and signs, hematological and biochemical parameters in children with joint hypermobility in a late period upon the Chornobyl NPP accident. Probl Radiac Med Radiobiol 2019; 24: 322-334, DOI: 10.33145/2304-8336-2019-24-322334.
14. Dajani AS, Ayoub E, Bierman FZ, et al. Guidelines for the diagnosis of rheumatic fever. Jones Criteria, 1992 update. Special Writing Group of the Committee on Rheumatic Fever, Endocarditis, and Kawasaki Disease of the Council on Cardiovascular Disease in the Young of the American Heart Association. JAMA 1992; 268: 2069-2073.

15. Szczygielska I, Hernik E, Kołodziejczyk B, et al. Rheumatic fever - new diagnostic criteria. Reumatologia 2018; 56: 37-41, DOI: 10.5114/reum.2018.74748.

16. Gewitz MH, Baltimore RS, Tani LY, et al. Revision of the Jones criteria for the diagnosis of acute rheumatic fever in the era of Doppler echocardiography: a scientific statement from the American Heart Association. Circulation 2015; 131: 18061818, DOI: 10.1161/CIR.0000000000000205.

17. Reményi B, Wilson N, Steer A, et al. World Heart Federation criteria for echocardiographic diagnosis of rheumatic heart disease: an evidence-based guideline. Nat Rev Cardiol 2012; 9: 297-309, DOI: 10.1038/nrcardio.2012.7.

18. Bouwien S-E, Klerks M, Kirby A. Beighton Score: A Valid Measure for Generalized Hypermobility in Children. J Pediatrics 2011; 158: 119-123.e4, DOI: 10.1016/j.jpeds.2010.07.021.

19. Sharaev PN, Pishkov VN, Solov'eva NI, et al. Method of determination of bound and free hydroxyproline in blood serum. Laboratornoe delo 1987; 5: 330-332 [in Russian].

20. Glesby MJ, Pyeritz RE. Association of mitral valve prolapse and systemic abnormalities of connective tissue. A phenotypic continuum. JAMA 1989; 262: 523-528.

21. Oshlyanskaya OA. Markers of the destruction of connective tissue in congenital and acquired pathologies in children. Perinatologiya i pediatriya 2009; 4: 57-61 [in Ukrainian].

22. Lawrie GM. Barlow disease: Simple and complex. J Thorac Cardiovasc Surg 2015; 150: 1078-1081, DOI: 10.1016/j. jtcvs.2015.09.030

23. Ferrer FS, Ferrer MLS, Murcia MDG, et al. Basic Study and Clinical Implications of Left Ventricular False Tendon. Is it associated with innocent murmur in children or heart disease? Rev Esp Cardiol 2015; 68: 700-705, DOI: 10.1016/j.rec.2014.09.021.

24. Marushchak M, Krynytska I, Mikolenko A, et al. Chronic heart failure causes osteopathy or is osteopathy a factor in development of chronic heart failure? Asian J Pharm Clin Res 2018; 11: 111-115, DOI:10.22159/ajpcr.2018.v11i1.17532.

25. Wang X, Wang W. Prevalence of Bicuspid Aortic Valve in Chinese Patients with Aortic Valve Disease: A Systematic Review. J Heart Valve Dis 2017; 26: 274-280. 